\title{
Taxonomic relationships within the fungal genus Pleurotus as determined by isoelectric focusing analysis of enzyme patterns
}

\author{
GEORGIOS ZeRVAKIS $\dagger$ and JACQUES LABARÈRE*
}

Laboratoire de Génétique Moléculaire et d'Amélioration des Champignons Cultivés, Université de Bordeaux II-INRA, CRA de Bordeaux, BP 81, 33883 Villenave d'Ornon Cedex, France

(Received 3 April 1991; revised 29 October 1991; accepted 11 November 1991)

\begin{abstract}
Isoenzymes from 23 isolates belonging to the fungal genus Pleurotus, subdivision Basidiomycotina, were examined by polyacrylamide gel isoelectric focusing and protein blotting. A numerical analysis was then done based on the zymograms for acid phosphatase, diaphorase, esterases, leucine aminopeptidase, phosphoglucomutase and phenoloxidases. The resulting dendrogram of taxonomic distances demonstrated the suitability of enzyme isoelectric focusing for use in systematics, as it clearly distinguished the four well-defined species $P$. cornucopiae, $P$. cystidiosus, $P$. eryngii and $P$. flabellatus. The species $P$. ostreatus, whose taxonomy is controversial, was separated from $P$. pulmonarius, and $P$. columbinus was classified as a distinct taxon. The delimitation of $P$. sajor-caju and $P$. sapidus strains appeared to be more difficult as they seemed to be closely related, the former with $P$. pulmonarius and the latter with $\boldsymbol{P}$. ostreatus. Isoenzymes also proved to be valuable for Pleurotus strain characterization. Their potential application for providing biochemical markers useful in taxonomy is discussed.
\end{abstract}

\section{Introduction}

The fungal genus Pleurotus (Fr.) Quél. is widely distributed throughout the world and is of particular economic importance as it comprises certain edible species that make up a steadily increasing part of the international mushroom market (Chang, 1984). The present taxonomy of the genus, however, is confusing and needs to be resolved.

A recent comprehensive review (Singer, 1986) on the systematics of basidiomycetes estimated the number of Pleurotus species to be between 35 and 43 . However, this is indicative only, as many controversies were reported; these arise from the fact that the taxonomy of Pleurotus has been based mainly on morphology and compatibility relationships. These criteria alone have been used to distinguish species such as $\boldsymbol{P}$. cornucopiae, $\boldsymbol{P}$. cystidiosus, $P$. dryinus, $P$. eryngii and $P$. flabellatus, but in other cases they are insufficient. For instance, $P$. ostreatus was distinguished from $P$. sapidus because the two are intersterile and have a different spore-print colour and host range (Anderson et al., 1973). However, Eger et al. (1979) contradicted the previous classification, after a

\footnotetext{
* Author for correspondence. Tel. 5684 3169; fax 56843274.

† Present address: Laboratory of General and Agricultural Microbiology, Agricultural University of Athens; Iera Odos 75, 11855 Athens, Greece.
}

comparative examination of basidiocarp features and interspecific crosses, stating that $P$. ostreatus and $P$. sapidus, together with $P$. pulmonarius and $P$. columbinus, belong to the same species. Hilber (1982) made a thorough study of the mating reactions as well as the microscopic and macroscopic characteristics of many Pleurotus isolates and concluded that $P$. pulmonarius and $P$. ostreatus were different species, $P$. sapidus is more likely to correspond to $P$. cornucopiae, and $P$. columbinus is simply a variety of $P$. ostreatus. There are other disagreements concerning the exact taxonomic position of the cultivar Pleurotus sp. florida (considered either as a $P$. pulmonarius or a $P$. ostreatus strain) and whether $P$. cystidiosus and $P$. abalonus belong to separate (Han et al., 1974; Bresinsky et al., 1987) or the same species (Jong \& Peng, 1975; Moore, 1985).

Meanwhile, biochemical and molecular biological approaches including studies of isoenzymes (Micales $e t$ al., 1986) and DNA restriction fragment length polymorphisms (Kozlowski \& Stepién, 1982) have been adopted and applied in fungal systematics. Studies utilizing enzyme electrophoresis have attempted to discriminate among species in genera such as Polyporus (Shannon et al., 1973), Fomes (Harris et al., 1974), Monilinia (Willets et al., 1977), Botrytis (Backhouse et al., 1984), Agaricus (Kerrigan \& Ross, 1988) and Phytophthora (Oudemans \& Coffey, 1991) or to characterize 
strains of Agaricus brunnescens (Royse \& May, 1982), Lentinus edodes (Royse et al., 1983; Ohmasa \& Furukawa, 1986), Volvariella volvacea (Royse et al., 1987) and Agaricus bitorquis (Roux \& Labarère, 1990).

In the present work, enzymes from 23 isolates belonging to nine Pleurotus species were examined with the aid of polyacrylamide gel electrophoresis isoelectric focusing (PAGE-IEF) and protein blotting. Eight different activities were tested and a numerical analysis of zymographic patterns was carried out. The aim was to test the suitability of this technique as a potential tool for use in fungal systematics and to contribute to Pleurotus taxonomy by providing some objective criteria useful for the species delimitation and characterization.

\section{Methods}

Biological material. All fungal isolates used in this study are dikaryotic strains belonging to nine species level taxa of the genus Pleurotus (Fr.) Quél., order Agaricales: P. columbinus (Quél. apud Bres.) Quél.; P. cornucopiae (Paul. ex Pers.) Roll.; P. cystidiosus O. K. Miller; P. eryngii (DC. ex Fr.) Quél.; P. flabellatus (Berk. \& Br.) Sacc.; $P$. ostreatus (Jacq. ex Fr.) Kummer; $P$. pulmonarius (Fr.) Quél.; $P$. sajorcaju (Fr.) Sing. and $P$. sapidus (Schulzer $\&$ Kalchbr.) Sacc. Details of the Pleurotus strains examined are presented in Table 1.
Culture media and conditions. The mycelial cultures were maintained and propagated on complete yeast medium (CYM) (Raper et al., 1972), comprising $\left(\mathrm{g}^{-1}\right)$ : glucose (20); bactopeptone (2); yeast extract (2); $\mathrm{MgSO}_{4} .7 \mathrm{H}_{2} \mathrm{O}(0.5) ; \mathrm{KH}_{2} \mathrm{PO}_{4}(0.46) ; \mathrm{K}_{2} \mathrm{HPO}_{4}$ (1) and agar (20). For electrophoresis, one Petri dish culture of each isolate was scraped with a scalpel to remove the surface mycelium, which was then transferred into test-tubes containing $10 \mathrm{ml} \mathrm{CYM}$, and disrupted with a Polytron homogenizer (Kinematica). The homogenate served as inoculum for liquid cultures in Roux flasks, containing $100 \mathrm{ml}$ CYM. The incubation lasted $15-20 \mathrm{~d}$ and took place under static conditions at $22^{\circ} \mathrm{C}$ in the dark. At least two independent cultures were performed for each isolate.

Preparation of protein samples. The mycelial cultures were harvested by filtration on sterile gauze, rinsed several times with cold distilled water and pressed dry between filter papers. The quantity of the mycelium obtained varied from 2 to $4 \mathrm{~g}$ per flask, depending on the strain.

Protein was extracted according to Roux \& Labarère (1990). After centrifugation ( $30 \mathrm{~min}, 4^{\circ} \mathrm{C}, 9000$ r.p.m.), the resulting supernatant was concentrated into a Centrisart I (Sartorius $\mathrm{GmbH}$ ) tube until a protein concentration of $10 \mathrm{mg} \mathrm{ml}^{-1}$ was achieved. The extracts were further stored at $-20^{\circ} \mathrm{C}$ as a $10 \%(\mathrm{v} / \mathrm{v})$ glycerol suspension.

Protein concentrations were determined according to Bradford (1976), using bovine serum albumin (fraction V-BRL) as standard.

Isoelectric focusing. A $7.5 \%$ (w/v) polyacrylamide gel, $0.5 \mathrm{~mm}$ thick, containing $3.5 \mathrm{~mm}$-glutamic acid and $2 \%(\mathrm{w} / \mathrm{v})$ ampholytes (Servalyt, pH 3-10) (Righetti, 1986) was fixed on one sheet of Gel Bond (FMC). The electrode buffers used were: for the cathode, 20 mM-arginine,

Table 1. Species, original host, geographical origin and source of the Pleurotus isolates examined

\begin{tabular}{|c|c|c|c|c|}
\hline Species & $\begin{array}{c}\text { Isolate } \\
\text { no. }\end{array}$ & $\begin{array}{l}\text { Host or } \\
\text { substrate }\end{array}$ & Origin* & Source $†$ \\
\hline \multirow[t]{2}{*}{ P. columbinus } & 16 & Unknown & France & ATCC 36498 (Vandendries) \\
\hline & 17 & Unknown & Italy & CBS 37351 (Baldacci) \\
\hline \multirow[t]{2}{*}{ P. cornucopiae } & 18 & Unknown & Germany & ATCC 38547 (Eger) \\
\hline & 19 & Ulmus sp. & Netherlands & CBS 38380 (van der Poel) \\
\hline \multirow[t]{2}{*}{ P. cystidiosus } & 11 & Ficus carica & C. Greece & LGAM P50 \\
\hline & 12 & Populus deltoides & USA & ATCC 28597 (Lombard) \\
\hline \multirow[t]{3}{*}{ P. eryngii } & 13 & Eryngium sp. & S. Greece & LGAM P63 \\
\hline & 14 & Field & N. Greece & LGAM P66 \\
\hline & 15 & Field & USSR & ATCC 36047 (Ginterova) \\
\hline \multirow{2}{*}{ P. flabellatus } & 20 & Rotting $\log$ & Unknown & ATCC 38138 (Graham) \\
\hline & 21 & Oil palm waste & Unknown & CBS 66585 \\
\hline \multirow{7}{*}{ P. ostreatus } & 4 & Fagus sp. & C. Greece & LGAM P38 \\
\hline & 5 & Populus sp. & C. Greece & LGAM P60 \\
\hline & 6 & Populus sp. & N. Greece & LGAM P61 \\
\hline & 7 & & & Commercial strain \\
\hline & 8 & Unknown & Germany & ATCC 32783 (Haider) \\
\hline & 9 & Unknown & Unknown & ATCC 34675 (Esser) \\
\hline & 10 & Unknown & Unknown & ATCC 38538 (Eger) \\
\hline \multirow[t]{3}{*}{ P. pulmonarius } & 1 & Fagus sp. & C. Greece & LGAM P26 \\
\hline & 2 & Unknown & USSR & ATCC 36050 (Ginterova) \\
\hline & 3 & Unknown & USA & CBS 13285 (Graauwmans) \\
\hline P. sajor-caju & 22 & Euphorbia royleana & India & ATCC 32078 (Rangaswami) \\
\hline$P$. sapidus & 23 & Hardwood & USA & ATCC 24986 (Petersen) \\
\hline
\end{tabular}

* The Pleurotus strains originating from Greece were isolated from three geographical areas: S, southern, C, central; $\mathbf{N}$, northern.

$\dagger$ ATCC, American Type Culture Collection, Rockville, Maryland, USA; CBS, Centraalbureau voor Schimmelcultures, Baarn, Holland; LGAM, Laboratory of General and Agricultural Microbiology, Agricultural University of Athens, Greece. The commercial strain of $P$. ostreatus is widely cultivated in mushroom farms throughout Europe. It is available to research workers from LGAM. 
$20 \mathrm{~mm}$-lysine and $10 \%(\mathrm{v} / \mathrm{v})$ ethylene diamine; for the anode, $20 \mathrm{mM}-$ aspartic acid and $20 \mathrm{~mm}$-glutamic acid (Radola, 1980). Isoelectric focusing was carried out at $4{ }^{\circ} \mathrm{C}$ on a flat bed apparatus (2117 Multiphor II, LKB) connected to a constant power supply. Prefocusing lasted $1 \mathrm{~h}$ at $10 \mathrm{~W}$. Then, $50 \mu \mathrm{l}$ of protein extract per isolate were deposited on the surface of the gel with $5 \times 10 \mathrm{~mm}$ filter-paper wicks (3MM, Whatman), along a line $1 \mathrm{~cm}$ away from the anode. Focusing was carried out at $10 \mathrm{~W}$ for $1 \mathrm{~h}$ and $15 \mathrm{~W}$ for $2 \mathrm{~h}$.

The $\mathrm{pH}$ gradient was determined by cutting out 25 consecutive pieces $(5 \times 10 \mathrm{~mm})$ from the gel, along the direction of the gradient, incubating them separately in $10 \mathrm{ml}$ of distilled-degassed water overnight and measuring the $\mathrm{pH}$, at $20^{\circ} \mathrm{C}$, with a Knick glass-type electrode. The $\mathrm{pH}$ values were plotted against the distance measured from the edge of the gel and the pI values of the enzyme bands were determined by interpolation from this curve.

Protein transfer and isoenzyme staining. The method for protein blotting onto nitrocellulose membranes (BA 85, Schleicher \& Schuell) was derived from the 'native blot' method of Reinhart \& Malamud (1982), as modified by Roux \& Labarère (1990). Phosphoglucomutase was the only enzyme among those examined that was detected directly on the gel.

After protein transfer $\left(2 \mathrm{~h}\right.$ at $\left.4{ }^{\circ} \mathrm{C}\right)$, the nicrocellulose membrane was incubated at room temperature in the appropriate enzyme staining solution, prepared as described below.

Acid phosphatase (APH; EC 3.1.3.2): $100 \mathrm{ml} \mathrm{0.1} \mathrm{M-citrate} \mathrm{buffer,}$ pH 5.0; $50 \mathrm{mg} \alpha$-naphthyl phosphate and $50 \mathrm{mg}$ Fast Garnet GBC salt (Lilly \& Charvat, 1987).

Diaphorase (DIA; EC 1.6.4.3): $100 \mathrm{ml} 0.2 \mathrm{M}$-Tris/HCl buffer, pH 8.0; $4 \mathrm{mg}$ 2,6-dichlorophenolindophenol; $10 \mathrm{mg} \mathrm{NADH}$ and $20 \mathrm{mg}$ 3-(4,5-dimethylthiazol-2-yl)-2,5-diphenyl-2H-tetrazolium bromide (MTT) (Allendorf et al., 1977; modified).

Esterases (EST; EC 3.1.1.1). Two types of esterase were detected.

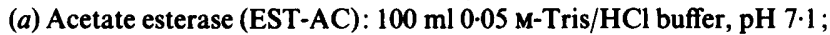
$50 \mathrm{mg} \alpha$-naphthyl acetate; $50 \mathrm{mg} \beta$-naphthyl acetate and $100 \mathrm{mg}$ Fast Blue RR salt. (b) Butyrate esterase (EST-BUT): as for acetate esterase, but with $\alpha$-naphthyl butyrate and $\beta$-naphthyl butyrate as substrates (Goullet \& Picard, 1984; modified).

Leucine aminopeptidase (LAP; EC 3.4.11.1): $100 \mathrm{ml} \mathrm{0.1} \mathrm{M-citrate}$ buffer, pH 5.2; $30 \mathrm{mg}$ L-leucine $\beta$-naphthylamide. $\mathrm{HCl} ; 10 \mathrm{mg} \mathrm{MgCl}_{2}$; $10 \mathrm{mg} \mathrm{MnCl}_{2}$ and $30 \mathrm{mg}$ Black $\mathrm{K}$ salt (Shaw \& Prasad, 1970; modified).

Phenoloxidases (PHE; EC 1.10.3.2). Two types of phenoloxidase were detected. (a) Dopa-reacting phenoloxidase (PHE-DRE): $100 \mathrm{ml}$ $0.1 \mathrm{M}$-phosphate buffer, pH 6.5 and $1.6 \mathrm{~g}$ DL-dihydroxyphenylalanine (dopa) (Choi et al., 1987). (b) Tolidine-reacting phenoloxidase (PHETRE): as for dopa-reacting phenoloxidase, but with $800 \mathrm{mg} o$-tolidine as substrate (Kerrigan \& Ross, 1988).

Phosphoglucomutase (PGM; EC 2.7.5.1): $100 \mathrm{ml} \mathrm{0 \cdot 1} \mathrm{M-Tris/HCl}$ buffer, pH 8.0; $20 \mathrm{mg}$ glucose 1-phosphate; $10 \mathrm{mg}$ NADP; 40 units glucose-6-phosphate dehydrogenase; $20 \mathrm{mg} \mathrm{MgCL} ; 10 \mathrm{mg}$ nitroblue tetrazolium (NBT) and $4 \mathrm{mg}$ phenazine methosulphate (PMS) (Allendorf et al., 1977; modified).

The incubation period was $20 \mathrm{~min}$ for EST-AC and LAP, $2 \mathrm{~h}$ for APH, EST-BUT and PGM and $8 \mathrm{~h}$ for DIA, PHE-DRE and PHETRE. Stained nitrocellulose sheets were photographed, and after drawing zymograms the sheets were preserved by drying. Each staining procedure was repeated at least three times, on separate gels, for each isolate.

Interpretation of data and statistical analysis. Isoenzyme banding patterns were recorded according to their migration along the polyacrylamide gel with a $\mathrm{pH}$ gradient, and each band was assigned a pI value.

A binomial matrix was employed to analyse variability and to transform band patterns for input into the sTAT-ITCF (version 4.0,
October 1988), software for statistical analysis written by the Institut Technique des Céréales et des Fourrages, (manual and software available upon request from, ITCF, 8 avenue du Président Wilson, 75116 Paris, France). The presence of a band at a particular position (pI) was designated ' 1 ', its absence at the same position was designated ' 0 ' (Smith \& Anderson, 1989). Variations in staining intensity, which certain bands occasionally presented, were not taken into account for the construction of this matrix. Taxonomic distances were computed according to Jaccard coefficients (Sneath \& Sokal, 1973). The distance values were further subjected to agglomerative hierarchical weighted group-average clustering to produce a dendrogram.

\section{Results}

\section{Reproducibility and appearance of banding patterns}

Each protein extract of a Pleurotus isolate was independently focused and stained at least three times, on separate gels, the extracts originating from at least two different mycelial cultures. All replicates of each strain produced invariant zymograms, apart from small differences concerning the intensity of certain bands. This electrophoretic technique proved to be particularly sensitive for enzyme detection and at the same time it offered good resolution for the majority of the activities tested. Only tolidine-reacting phenoloxidase bands had a tendency to diffuse, but they remained interpretable. Protein blotting onto nitrocellulose membranes prior to staining resolved many of the difficulties. Representative patterns of four enzyme activities are presented (Fig. 1).

\section{Zymograms and pI ranges of the 23 Pleurotus isolates}

Acid phosphatase. A total of fifteen bands was detected within a $\mathrm{pH}$ range of $5 \cdot 16-6 \cdot 69$ (Fig. $2 a$ ). The 23 isolates were found to possess from one to seven bands each. Only strains 13 and 15 shared the same pattern. The $P$. eryngii phenotype was characterized by the appearance of three distinct bands at $\mathrm{pH}$ values of 6.15, 6.45 and 6.69. $P$. cystidiosus isolates alone (11 and 12) had a band with $\mathrm{pI}=6 \cdot 30$. Strains 20 and 21 , belonging to $P$. flabellatus, had a unique combination of bands with $\mathrm{pH}$ values of 5.70 and 6.06 that permitted this species to be distinguished from the others studied.

Diaphorase. Eleven bands with pI values between 4.50 and 6.30 were visualized (Fig. $2 b$ ). Each Pleurotus isolate gave from one to seven bands of enzyme activity. Common patterns were observed between the 11-12, 13-15 and 22-23 pairs of strains leading to the formation of 20 phenotypic classes. $P$. cornucopiae isolates (18 and 19) were identified by a band with $\mathrm{pI}=4.50$, while strains belonging to $P$. eryngii $(13,14$ and 15$)$ shared a band with a pI value of 4.65. The strains of $P$. pulmonarius (1,2 and 3 ) were distinguished on the basis of 


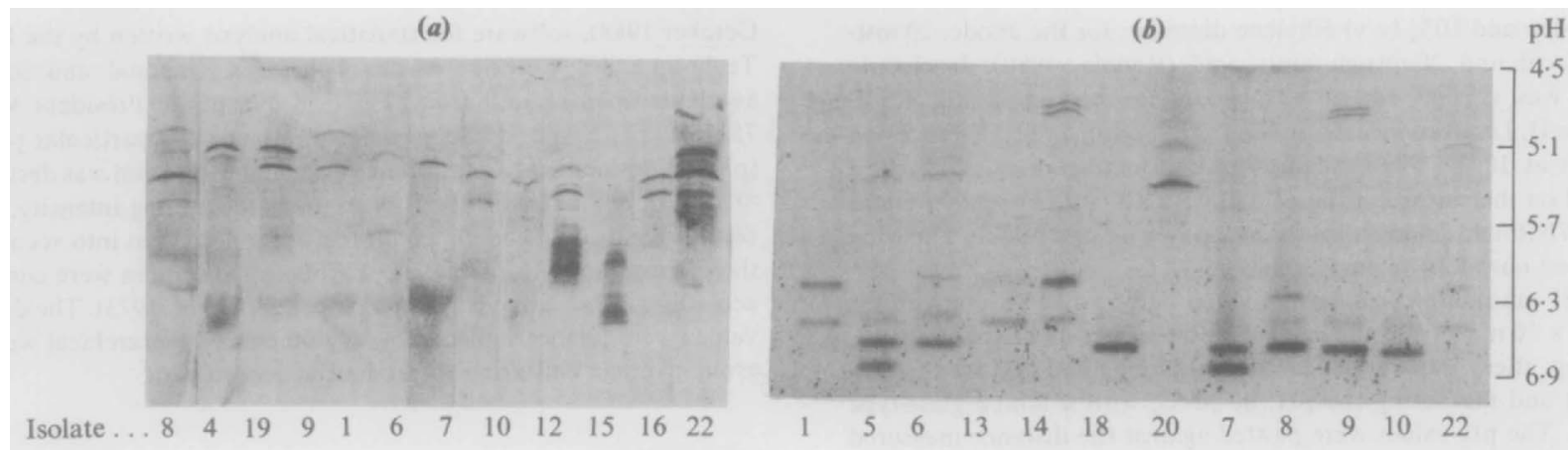

(c)

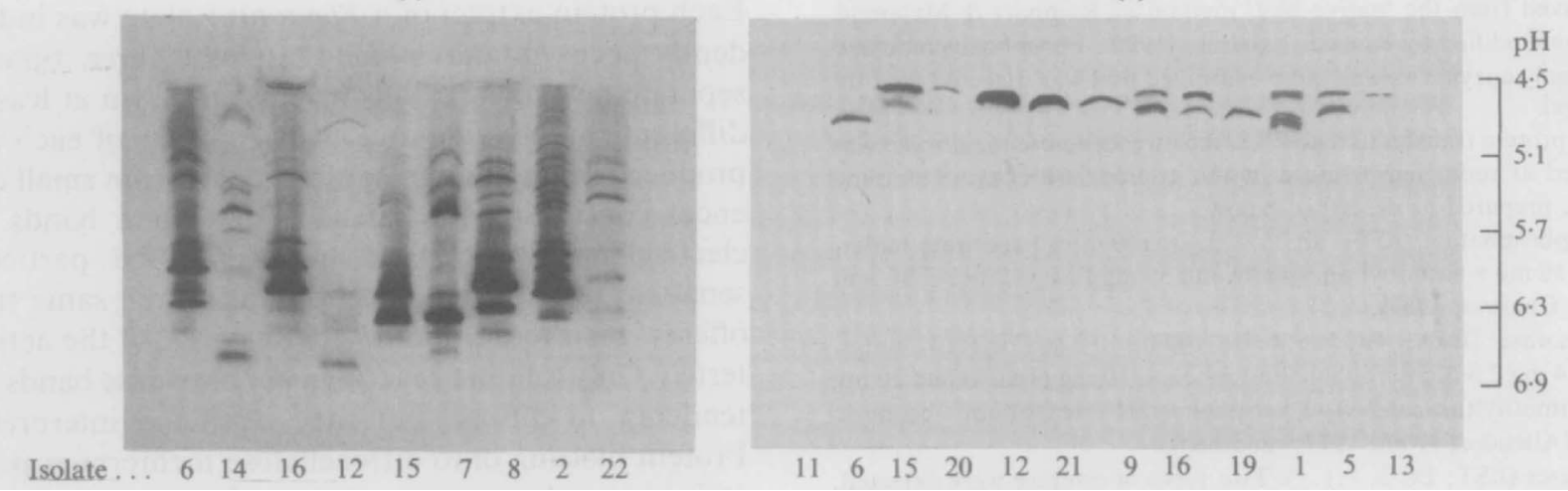

Fig. 1. Representative zymograms, detected on nitrocellulose membranes, for different Pleurotus isolates. (a) Acid phosphatase; (b) butyrate esterase; $(c)$ acetate esterase; $(d)$ leucine aminopeptidase. Isolates are numbered as in Table 1.

the simultaneous presence of two bands with pI values of 5.91 and 6.30. In addition, a single band at $\mathrm{pI}=6.24$ appeared to be quite characteristic for $P$. cystidiosus.

Acetate esterase. Forty-one distinct bands were observed for this highly polymorphic enzyme in a $\mathrm{pH}$ range of 4.56-7.05 (Fig. 3a). The isolates possessed from 5 to 21 bands each, and all electrophoretic phenotypes were found to be unique. $P$. flabellatus strains were characterized by the presence of a band with $\mathrm{pI}=7.05$. Isolates 16 and 17 belonging to $P$. columbinus shared a band combination, with pI values of $6 \cdot 21,6.45$ and 6.60 , which did not exist among the rest of Pleurotus strains examined.

Butyrate esterase. Fourteen bands were detected with pI values of 4.53-6.90 (Fig. 3b). Pleurotus isolates gave from one to eleven bands each. Only P. cystidiosus strains shared an identical pattern appearing in the narrow $\mathrm{pH}$

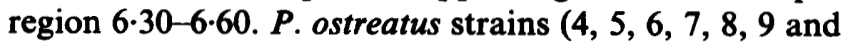
10) were separated on the basis of a two-band pattern with $\mathrm{pI}$ values of $5 \cdot 70$ and 6.78 .

Leucine aminopeptidase. Nine bands were recorded ranging in $\mathrm{pH}$ from $4 \cdot 59-4.89$ (Fig. $4 a$ ). The strains tested possessed from one to five bands each. The same patterns were found among the following isolates: 4,10 , $18 ; 5,6 ; 7,16 ; 9,23 ; 13,14,15$; and 20,21 . Consequently, 15 phenotypic classes were distinguished. A band with a $\mathrm{pI}=4.68$ characterized the $P$. flabellatus isolates, while $P$. eryngii strains were distinguished by the presence of a single band at $\mathrm{pH}=4.59$.

Phosphoglucomutase. Six bands were detected within a pH range of 4.65-5.43 and the isolates gave from one to three bands each (Fig. 4b). Identical phenotypes were observed for the following groups of strains: 1,$16 ; 2,3,7$, $9 ; 4,5,6,8 ; 18,19,23 ; 10,22 ; 13,14,15$; and $20,21$. Consequently, nine distinct electrophoretic groups were identified for this activity. Species such as P. cystidiosus, $P$. eryngii and $P$. flabellatus could be identified by bands of $\mathrm{pI}=5.43, \mathrm{pI}=5.25$ and $\mathrm{pI}=4.65$ respectively.

Dopa-reacting phenoloxidase. A total of 16 bands were visualized with $\mathrm{pI}$ values of 4.65-6.51 and isolates were found to possess from one to ten bands each (Fig. 5a). The sole common band, of $\mathrm{pI}=5 \cdot 16$, was shared by strains 18 and 19. This enzyme established specific band combinations for $P$. columbinus $(\mathrm{pI}=4.65$ and $\mathrm{pI}=4.74)$, 


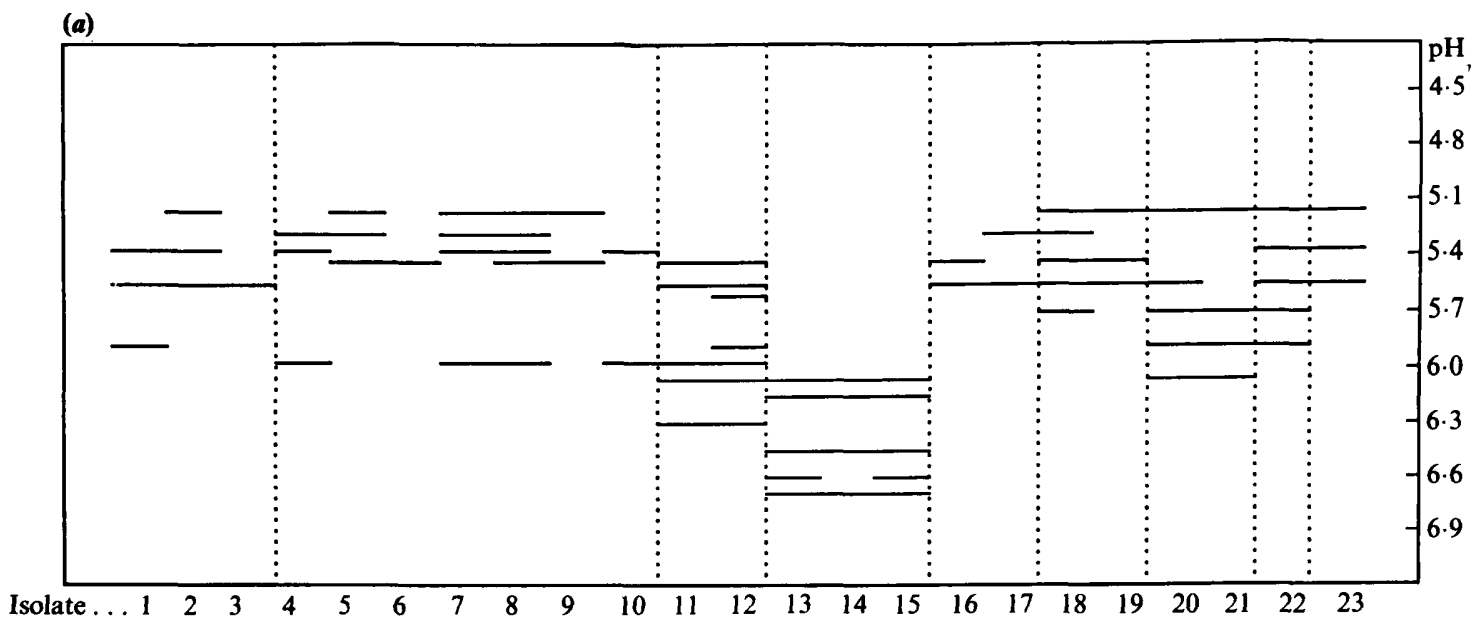

(b)

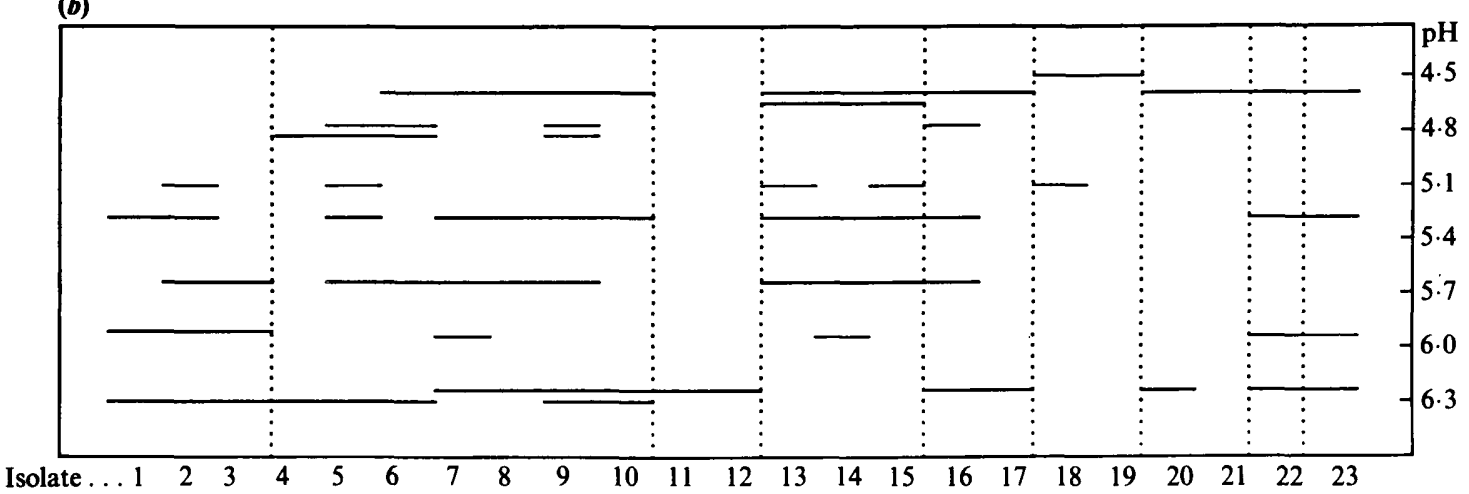

Fig. 2. Diagrammatic representation of zymograms for 23 Pleurotus isolates of (a) acid phosphatase and (b) diaphorase. Each protein extract of these strains was independently focused and stained at least three times, on separate gels, originating from at least two independent mycelial cultures. The isolates appear numbered as in Table 1. Dotted lines separate the taxa examined.

$P$. cystidiosus $(\mathrm{pI}=5 \cdot 10$ and $\mathrm{pI}=5 \cdot 22)$ and $P$. sapidus ( $\mathrm{pI}=4.65$ and $\mathrm{pI}=6 \cdot 18)$. It was also possible to distinguish $P$. cornucopiae strains from their single-band pattern $(\mathrm{pI}=5 \cdot 16)$.

Tolidine-reacting phenoloxidase. Nineteen bands were observed ranging in pI from 4.44-6.60; the isolates gave from 3 to 12 bands each and have unique electrophoretic phenotypes (Fig. $5 b$ ). This activity produced one common band for all the strains examined $(\mathrm{pI}=4 \cdot 50) . P$. eryngii isolates were characterized by two unique bands with pI values of 5.64 and 5.70.

\section{Numerical analysis of zymograms}

A distance matrix, based on the electrophoretic phenotypes of the Pleurotus isolates studied, was generated using the Jaccard coefficient and the levels of taxonomic distance between the strains are shown in Table 2. The resulting dendrogram, produced after group-average clustering, illustrates the relationships found among Pleurotus species (Fig. 6). According to the dendrogram, the strains formed five clusters at $D=0.68(68 \%)$ containing four taxonomically well-separated species, i.e. $P$. cornucopiae, $P$. eryngii, $P$. flabellatus and $P$. cystidiosus, together with one larger group including the rest of the taxa examined (the $D=0.68$ value was selected, as at this particular distance the four previously mentioned species were clearly distinguished). Isolates belonging to $P$. cornucopiae, $P$. eryngii and $P$. flabellatus established tight intraspecific bonds at distance values of $40 \%$ and lower. However, $P$. cystidiosus strains proved to be less related $(D=0.67)$. The large, fifth group previously mentioned could be separated into two subgroups. The first contained $P$. sajor-caju and isolate 10 (originally classified as $P$. ostreatus), which separated at a distance of $60 \%$. The second subgroup could be divided into two smaller clusters, one including all $P$. pulmonarius strains, the other $P$. ostreatus, $P$. columbinus 
(a)

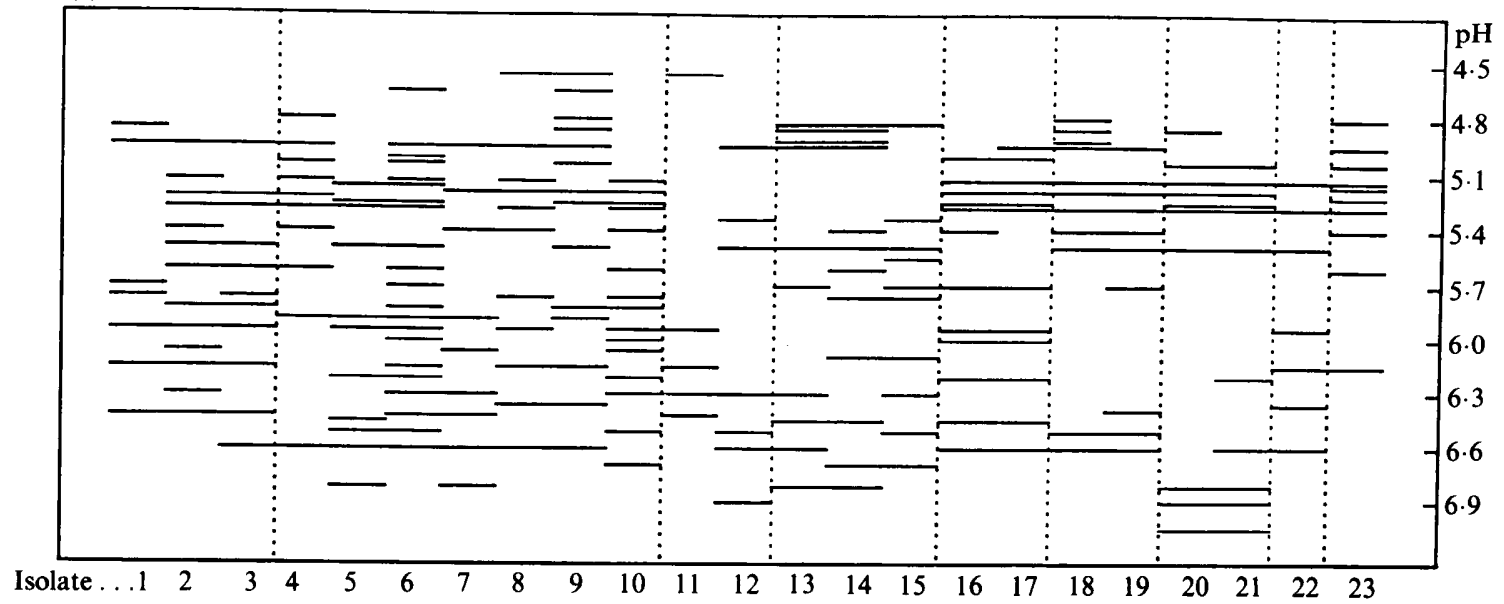

(b)

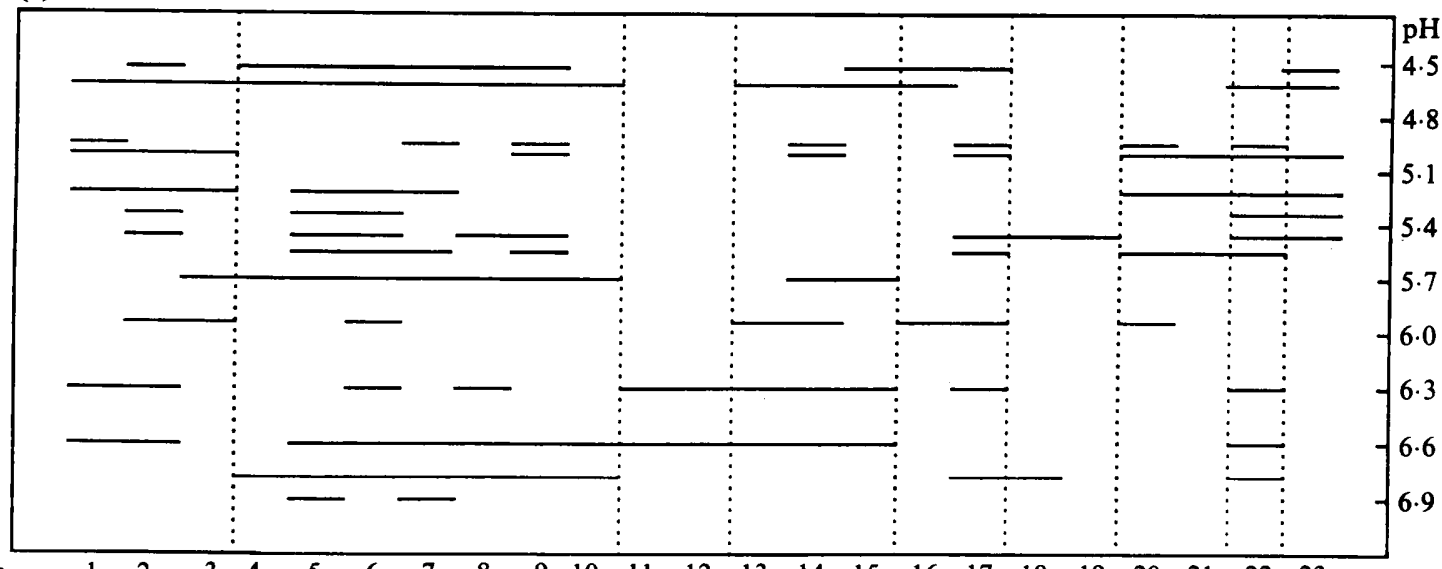

$\begin{array}{llllllllllllllllllllllllll}\text { Isolate } \ldots . . & 1 & 2 & 3 & 4 & 5 & 6 & 7 & 8 & 9 & 10 & 11 & 12 & 13 & 14 & 15 & 16 & 17 & 18 & 19 & 20 & 21 & 22 & 23\end{array}$

Fig. 3. Diagrammatic representation of zymograms for 23 Pleurotus isolates of $(a)$ acetate esterase and $(b)$ butyrate esterase. Details as for Fig. 2.

(a)

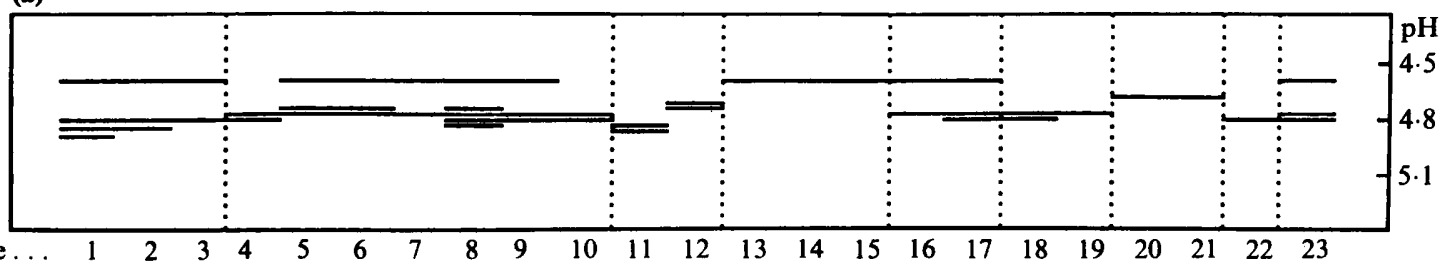

(b)

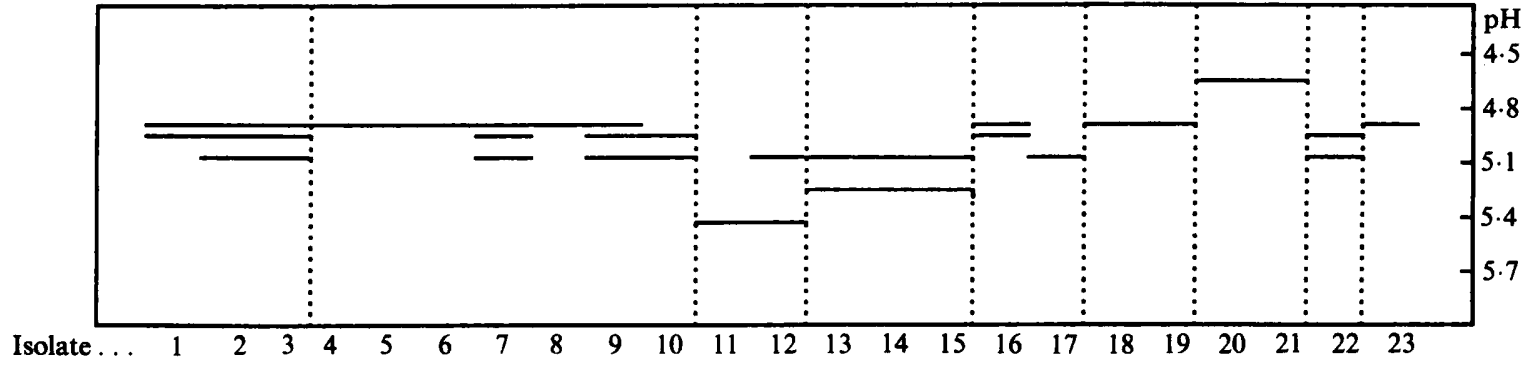

Fig. 4. Diagrammatic representation of zymograms for 23 Pleurotus isolates of (a) leucine aminopeptidase and (b) phosphoglucomutase. Details as for Fig. 2. 
(a)

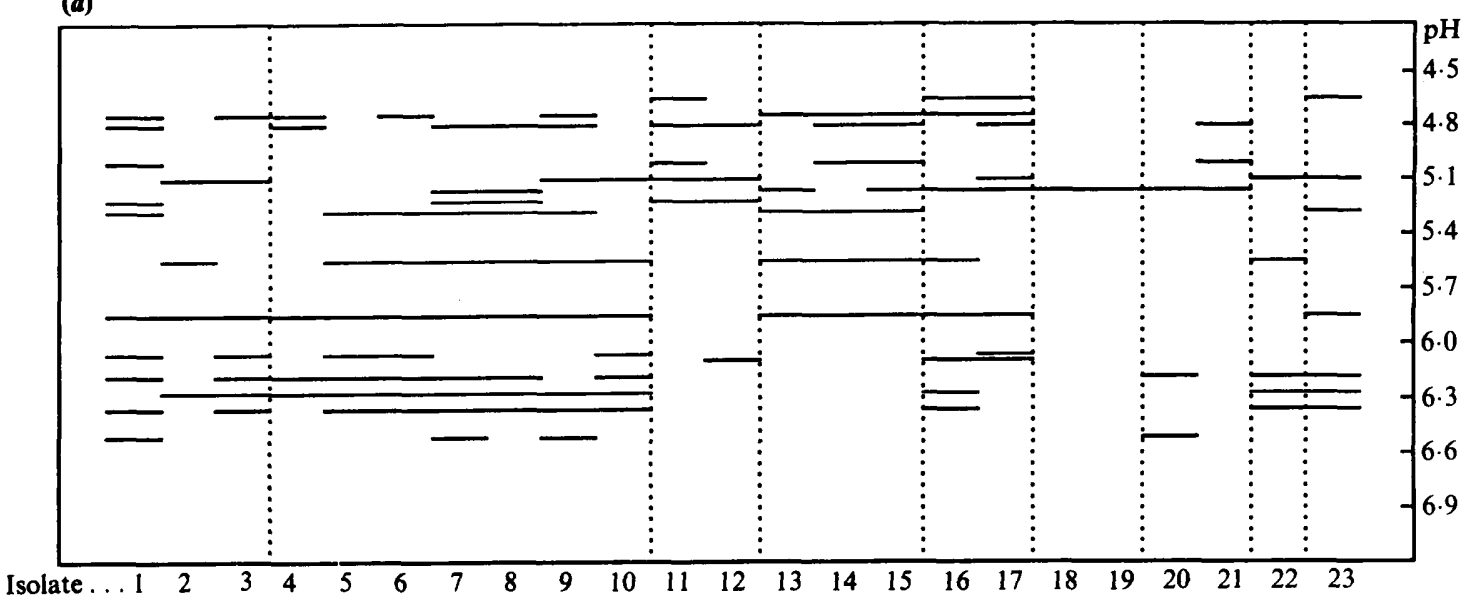

(b)

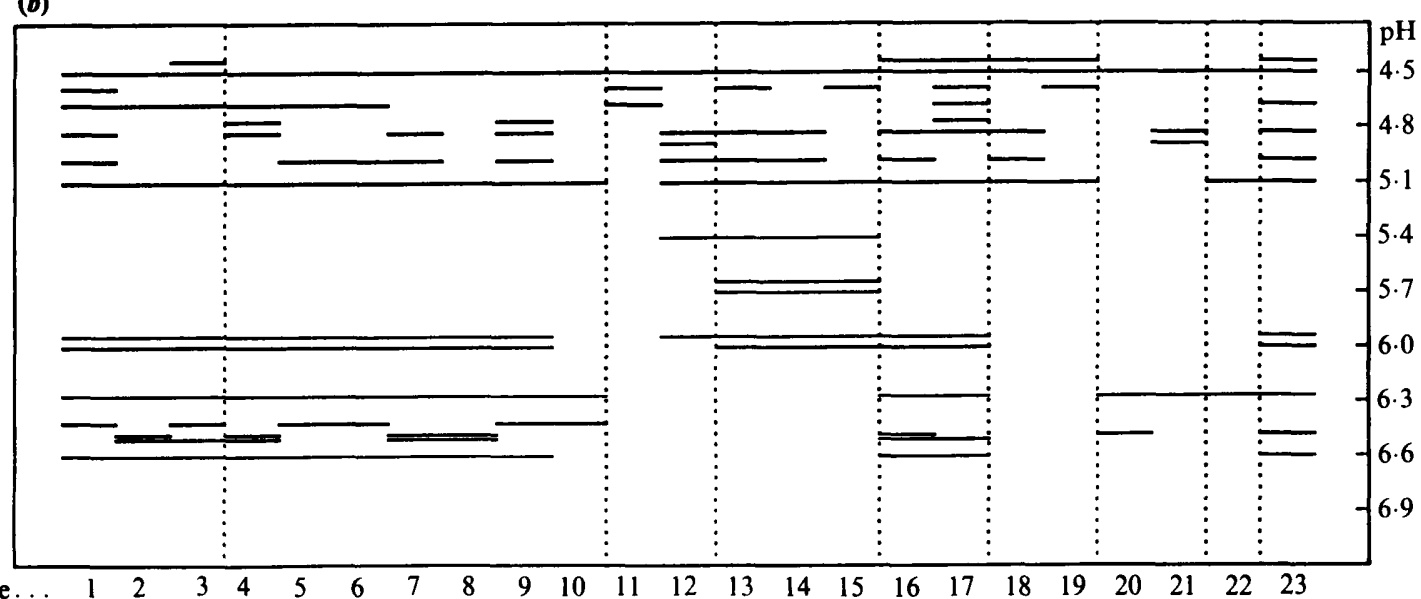

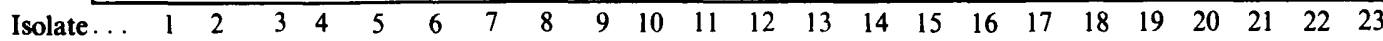

Fig. 5. Diagrammatic representation of zymograms for 23 Pleurotus isolates of $(a)$ dopa-reacting phenoloxidase and $(b)$ tolidinereacting phenoloxidase. Details as for Fig. 2.

Table 2. Jaccard's coefficients of taxonomic distance among 23 Pleurotus isolates based on electrophoretic banding patterns for eight enzymes

\begin{tabular}{|c|c|c|c|c|c|c|c|c|c|c|c|c|c|c|c|c|c|c|c|c|c|c|}
\hline & 1 & 2 & 3 & 4 & 5 & 6 & 7 & 8 & 9 & 10 & 11 & 12 & 13 & 14 & 15 & 16 & 17 & 18 & 19 & 20 & 21 & 22 \\
\hline 2 & 597 & & & & & & & & & & & & & & & & & & & & & \\
\hline 3 & 550 & 439 & & & & & & & & & & & & & & & & & & & & \\
\hline 4 & 727 & 635 & 638 & & & & & & & & & & & & & & & & & & & \\
\hline 5 & 685 & 639 & 642 & 687 & & & & & & & & & & & & & & & & & & \\
\hline 6 & 654 & 573 & 551 & 653 & 348 & & & & & & & & & & & & & & & & & \\
\hline 7 & 620 & 611 & 690 & 594 & 563 & 630 & & & & & & & & & & & & & & & & \\
\hline 8 & 662 & 594 & 657 & 574 & 586 & 579 & 446 & & & & & & & & & & & & & & & \\
\hline 9 & 627 & 654 & 620 & 623 & 554 & 494 & 507 & 548 & & & & & & & & & & & & & & \\
\hline 10 & 757 & 652 & 656 & 705 & 681 & 630 & 632 & 615 & 658 & & & & & & & & & & & & & \\
\hline 11 & 776 & 823 & 881 & 914 & 929 & 880 & 868 & 806 & 877 & 862 & & & & & & & & & & & & \\
\hline 12 & 818 & 841 & 859 & 871 & 861 & 833 & 800 & 809 & 813 & 859 & 674 & & & & & & & & & & & \\
\hline 13 & 743 & 750 & 797 & 857 & 757 & 738 & 712 & 770 & 731 & 863 & 902 & 767 & & & & & & & & & & \\
\hline 14 & 686 & 730 & 757 & 833 & 769 & 765 & 693 & 750 & 696 & 808 & 908 & 800 & 340 & & & & & & & & & \\
\hline 15 & 764 & 770 & 817 & 875 & 776 & 756 & 750 & 740 & 765 & 800 & 867 & 790 & 365 & 411 & & & & & & & & \\
\hline 16 & 736 & 652 & 656 & 683 & 623 & 575 & 594 & 554 & 622 & 677 & 906 & 851 & 721 & 770 & 795 & & & & & & & \\
\hline 17 & 694 & 685 & 652 & 656 & 711 & 628 & 684 & 634 & 636 & 729 & 841 & 806 & 750 & 779 & 803 & 475 & & & & & & \\
\hline 18 & 846 & 797 & 833 & 686 & 803 & 827 & 773 & 742 & 771 & 793 & 941 & 827 & 817 & 864 & 909 & 767 & 738 & & & & & \\
\hline 19 & 867 & 814 & 833 & 776 & 857 & 826 & 825 & 776 & 855 & 811 & 907 & 851 & 857 & 921 & 879 & 759 & 750 & 406 & & & & \\
\hline 20 & 848 & 853 & 855 & 867 & 873 & 844 & 794 & 855 & 808 & 836 & 900 & 873 & 875 & 866 & 926 & 810 & 781 & 796 & 818 & & & \\
\hline 21 & 879 & 899 & 887 & 842 & 853 & 840 & 824 & 868 & 819 & 850 & 896 & 824 & 871 & 862 & 891 & 823 & 774 & 787 & 810 & 389 & & \\
\hline 22 & 698 & 600 & 672 & 787 & 716 & 699 & 687 & 629 & 632 & 600 & 827 & 807 & 836 & 829 & 855 & 754 & 708 & 750 & 792 & 680 & 745 & \\
\hline 23 & 646 & 548 & 617 & 545 & 667 & 616 & 597 & 556 & 586 & 683 & 883 & 862 & 817 & 778 & 851 & 574 & 657 & 685 & 745 & 780 & 833 & 607 \\
\hline
\end{tabular}




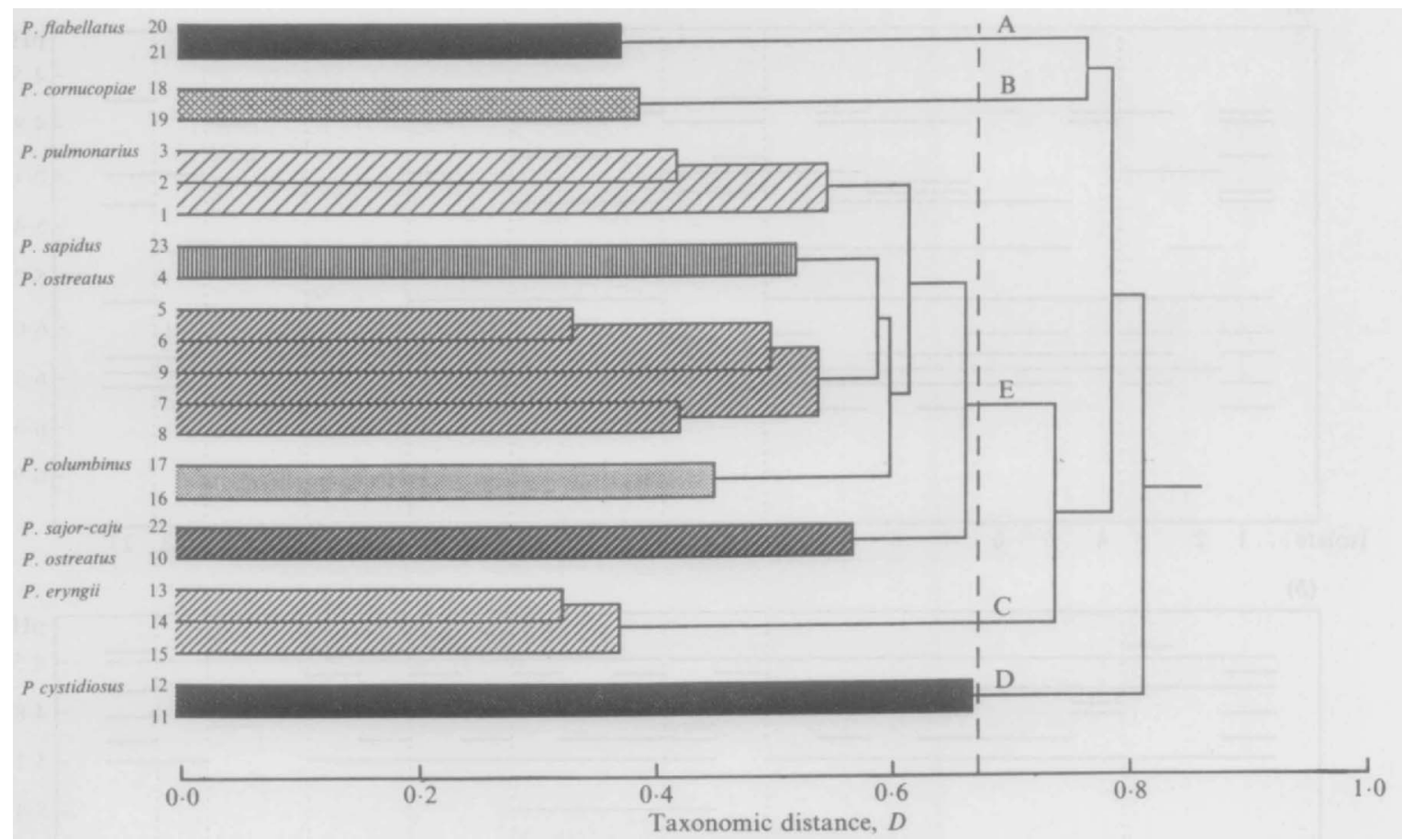

Fig. 6. Taxonomic relationships among Pleurotus isolates as visualized after weighted group-average clustering. This dendrogram was computed from the Jaccard's coefficients of taxonomic distance (Table 2). The dashed line indicates the level of taxonomic distance $(D=0.68)$ that permits the classification of the total Pleurotus isolates into five clusters A, P. flabellatus; B, P. cornucopiae; C, P. eryngii; D, $P$. cystidiosus; E, the larger group containing the rest of the taxa studied.

and $P$. sapidus. Within the latter, there was a relatively high degree of similarity $(D<0.55)$ among $P$. ostreatus isolates $5,6,7,8$ and 9 . $P$. columbinus strains appeared closely related $(D=0.48)$ and further linked with the $P$. ostreatus complex. A relative affinity to the last group was demonstrated also by the $P$. sapidus isolate, primarily classified with strain 4 and subsequently attached to the rest of this species $(D=0.60)$.

\section{Discussion}

In the present study, eight isoenzyme activities were analysed, following isoelectric focusing and protein blotting, to provide valid biochemical criteria useful for taxonomic application in the fungal genus Pleurotus. Strains were obtained from various geographical areas throughout the world, in order to ensure a genetic diversity representative of the species concerned. Each isolate used had already been identified by application of morphological and physiological criteria (Zervakis \& Balis, 1991). It should also be noted that these findings were in agreement with the original identifications made by those supplying the isolates (Table 1).

According to the results obtained, most of the enzyme activities demonstrated considerable levels of intra- specific variability. The highest diversity between and within species was observed for acetate esterase patterns. All isolates produced distinctive zymograms capable of discriminating among them. Zymograms of similar appearance, though slightly less complex, were recorded for butyrate esterase. The high polymorphism found for esterases seems to be a quite common phenomenon in basidiomycetes (Ohmasa \& Furukawa, 1986; Roux \& Labarère, 1991). Apparently, such activities might potentially serve as biochemical markers for the registration and protection of commercial Pleurotus strains, as already demonstrated for Lentinus edodes (Royse et al., 1983) and Agaricus bitorquis (Roux \& Labarère, 1990). Phenoloxidases also appeared to produce characteristic patterns at the intraspecific level; they could thus be used for systematic studies after numerical analysis. This accords well with the findings of Kerrigan \& Ross (1988) concerning laccases of the genus Agaricus. The other enzymes tested presented less variability; therefore, their taxonomic value would seem to be in the provision of simple-to-interpret electrophoretic phenotypes. Leucine aminopeptidase and phosphoglucomutase, in particular, were found to be largely invariant within species such as $P$. flabellatus, $P$. eryngii and $P$. cornucopiae.

Statistical treatment of the zymograms revealed large taxonomic distances among the isolates studied, particu- 
larly within the species $P$. ostreatus (e.g. $D>0.65$ for strains $4-5$ and 5-10). The large diversity among $P$. ostreatus strains has been pointed out previously (Kulkarni et al., 1986; May \& Royse, 1988). In the former study, the levels of similarity were found to be as low as 0.15 among two isolates and the rest of the 30 strains examined (this value could, however, be attributed to the broad species concept adopted by the authors). In the latter study, a high divergence was found in spite of the fact that only loci with minimal intraspecific variation were taken into account. Within species of other genera, distances of similar order have been reported for Agaricus campestris (May \& Royse, 1982), whilst lower values occur more often, as demonstrated in fungi such as Lentinus edodes (Royse et al., 1989), Botrytis cinerea (Backhouse et al., 1984) and Phytophthora cambivora (Oudemans \& Coffey, 1991). The relatively high polymorphism obtained here is due to the resolving power of the electrophoretic method applied (Righetti, 1986), the nature of the isoenzymes examined, and most of all to the wide geographical distribution and the wild origin of the isolates used.

Classification based on cluster analysis confirmed, up to a certain point, the original identification of the Pleurotus isolates by assigning them into five larger taxonomic groups. Four of them corresponded to welldefined species such as $\boldsymbol{P}$. cornucopiae, $\boldsymbol{P}$. flabellatus, $\boldsymbol{P}$. eryngii and $P$. cystidiosus. Their constituting members formed tight groups $(D<0.40)$ that were well-separated from each other and from the rest of the species studied. A possible exception could be the two $P$. cystidiosus isolates which appeared to share a relatively high value for taxonomic distance $(D=0.67)$. Nevertheless, the presence of synnematoid fructifications in both mycelial cultures (Zervakis \& Balis, 1991) leaves no doubt as to whether they have been properly assigned and any numeric dissimilarity they possess should be attributed to their distant origins. The last wide cluster contained five taxa, $P$. sajor-caju, $P$. ostreatus, $P$. pulmonarius, $P$. sapidus and $P$. columbinus, that demonstrated closer zymographic relationships and their delimitation was more complicated. Among them, $P$. sajor-caju was the first to be distinguished from the other Pleurotus species, despite presenting a certain affinity to $P$. pulmonarius isolates. Its existence in the same dendrogram class as a $P$. ostreatus strain was due rather to the tendency of the clustering process to form groups and to the high polymorphism demonstrated by this latter species. Previous morphological and compatibility studies concerning the rest of the Pleurotus species examined had been often controversial and a definitive conclusion had been hard to reach (Anderson et al., 1973; Manning, 1977; Eger et al., 1979; Bresinsky et al., 1987). The present investigation, however, permitted the separation of $P$. pulmonarius from $P$. ostreatus isolates as their respective clusters were found to be distinct. This outcome is in accordance with the findings of a preceding taxonomic study which applied morphological and physiological criteria to distinguish strains from these two species (Zervakis \& Balis, 1991). As concerns $P$. columbinus, the results demonstrated that it could be regarded as a separate taxon. Up till now it was considered as a variety of $\boldsymbol{P}$. ostreatus (Singer, 1986), mainly because the two are sexually compatible with each other (Eger et al., 1979; Hilber, 1982). Nevertheless, morphological differences do exist among them (Hilber, 1982), as well as intersterile matings (Bresinsky et al., 1977). Thus, although it is certain that these two taxa are closely related, whether they belong to the same species or not remains in doubt. The taxonomic position of $\boldsymbol{P}$. sapidus appeared to be bewildering. Isoenzyme patterns suggested a slightly higher similarity with $P$. ostreatus than with $P$. pulmonarius. As this taxon has been reported to exist only in the American continent (Anderson et al., 1973; Manning, 1977), it is probably on its way to speciation. The assumptions made for $P$. sajor-caju and $P$. sapidus were further supported by the outcome of interspecific matings concerning the species in question (C. Balis, personal communication).

The results of the present study indicate another potential application of enzyme isoelectric focusing in fungal systematics. Electrophoretic phenotypes distinguished by particular enzyme bands with species-specific pI values would be demonstrated. Thus, $P$. ostreatus was characterized by a two-band pattern $(\mathrm{pI}=5.70$ and $\mathrm{pI}=6.78)$ for butyrate esterase activity. As concerns the rest of the Pleurotus species examined, the observations made have an indicative value only due to the relatively limited number of isolates used. In this latter case, for instance, $P$. eryngii isolates were identified by bands of activities such as acid phosphatase $(\mathrm{pI}=6.15 ; \mathrm{pI}=6.45$ and $p I=6.69)$, diaphorase $(p I=4.65)$, leucine aminopeptidase $(\mathrm{pI}=4.59)$, phosphoglucomutase $(\mathrm{pI}=5.25)$ and tolidine-reacting phenoloxidase $(\mathrm{pI}=5.64$ and $\mathrm{pI}=5.70$ ). The presence of similar isoenzyme markers has already been demonstrated in the genus Agaricus (May \& Royse, 1981; Kerrigan \& Ross, 1988). These data indicate that this method might be appropriate for the development of molecular markers useful in systematics. The establishment of appropriate taxonomic criteria, through the right selection and combination of activities producing constant biochemical characters, is feasible and of importance.

The use of isoelectric focusing analysis of zymograms in fungal taxonomy has rarely been reported, but the present work clearly demonstrates its suitability. It presented a clear delimitation of unambiguous species ( $P$. cornucopiae, $P$. cystidiosus, $P$. eryngii and 
P. flabellatus), and at the same time permitted a thorough insight within the taxa in question. Thus, $P$. ostreatus was distinguished from $P$. pulmonarius and $P$. sajor-caju, the last two appearing related. Throughout this study, $P$. sapidus was linked with $P$. ostreatus to a greater extent than was $P$. columbinus; this latter formed a distinct taxon. The banding patterns obtained proved further that they could provide the means to characterize Pleurotus strains with precision and dependability.

We thank Professor C. Balis (Agricultural University of Athens) for kindly providing Pleurotus isolates used in this investigation. The valuable contribution of P. Roux, B. Iraçabal and J.-C. Vible to this study is greatly acknowledged. The present work was financially supported by grants from the Conseil Scientifique de l'Université de Bordeaux II, the Institut National de la Recherche Agronomique, the Lur Berri Food Company and by an Erasmus-EEC fellowship.

\section{References}

Allendorf, F. W., Mitchell, N., Ryman, N. \& Stahl, G. (1977). Isozyme loci in brown trout (Salmo trutta L.): detection and interpretation from population data. Hereditas 86, 179-190.

Anderson, N., Wang, S. S. \& Schwandt, J. W. (1973). The Pleurotus ostreatus-sapidus species complex. Mycologia 65, 28-35.

BACKhouse, D., WilleTs, H. J. \& ADAM, P. (1984). Electrophoretic studies of Botrytis species. Transactions of the British Mycological Society $82,625-630$.

BRADFORD, M. M. (1976). A rapid and sensitive method for the quantitation of microgram quantities of protein utilizing the principle of protein-dye binding. Analytical Biochemistry 72, 248-254.

Bresinsky, A., Hilber, O. \& Molitoris, H. P. (1977). The genus Pleurotus as an aid for understanding the concept of species in Basidiomycetes. In The Species Concept in Hymenomycetes, pp. 209-250. Edited by H. Clémençon. Vaduz: J. Cramer.

Bresinsky, A., Fischer, M., MeIXNer, B. \& PAulus, W. (1987). Speciation in Pleurotus. Mycologia 79, 234-245.

Chang, S. T. (1984). Conversion of agricultural and industrial wastes into fungal protein. Conservation and Recycling 7, 175-180.

CHOI, H. T., WILKs, R. L. \& Ross, I. K. (1987). Formation of sclerotia in liquid cultures of Coprinus congregatus and their phenoloxidase isozymes. Mycologia 79, 166-172.

Eger, G., LI, S. F. \& Leal-Lara, H. (1979). Contribution to the discussion on the species concept in the Pleurotus ostreatus complex. Mycologia 71, 577-588.

Goullet, Ph. \& Picard, B. (1984). Distinctive electrophoretic and isoelectric focusing patterns of esterases from Yersinia enterocolitica and Yersinia pseudotuberculosis. Journal of General Microbiology 130 , 1471-1480.

HaN, Y. H., Chen, K. M. \& Cheng, S. (1974). Characteristics and cultivation of a new Pleurotus in Taiwan. Mushroom Science 9, $167-174$.

Harris, J. W., Ballal, S. K. \& Daniel, V. S. (1974). Starch gel electrophoresis of certain enzymes from five species of Fomes. Biochemical Systematics and Ecology 2, 53-57.

Hilber, O. (1982). Die Gattung Pleurotus (Fr.) Kummer unter besonderer Berücksichtigung des Pleurotus eryngii-Formenkomplexes. Bibliotheca Mycologica 87, 1-448.

JoNG, S. C. \& PENG, J. T. (1975). Identity and cultivation of a new commercial mushroom in Taiwan. Mycologia 67, 1235-1238.

Kerrigan, R. W. \& Ross, I. K. (1988). Extracellular laccases: biochemical markers in Agaricus systematics. Mycologia 80, 689-695.
KozLowsKı, M. \& STEPIÉN, P. P. (1982). Restriction enzyme analysis of mitochondrial DNA of members of the genus Aspergillus as an aid in taxonomy. Journal of General Microbiology 128, 471-476.

KulKarn, R. K., Kamerath, C. D. \& AllReD, K. L. (1986). Genetic diversity between isolates of Pleurotus ostreatus as revealed by isozyme analysis. In Developments in Crop Science 10: Cultivating Edible Fungi, pp. 171-181. Edited by P. J. Wuest, D. J. Royse \& R. B. Beelman. Amsterdam: Elsevier Press.

Lilly, W. W. \& Charvat, I. (1987). Activities and isozymes of acid phosphatase in Schizophyllum commune: a re-examination. Mycologia 79, 314-319.

MaNNING, D. L. (1977). Fruiting and mating compatibility studies in the Pleurotus ostreatus-sapidus complex. In 2nd International Mycological Congress Abstracts, p. 415. Edited by H. E. Bigelow \& E. G. Simmons. Tampa, Florida: IMC-2 Inc.

MAY, B. \& RoYsE, D. J. (1981). Application of the electrophoretic methodology to the elucidation of genetic life histories of edible mushrooms. Mushroom Science 11, 799-817.

MAY, B. \& RoYse, D. J. (1982). Genetic variation and joint segregation of biochemical loci in the common meadow mushroom, Agaricus campestris. Biochemical Genetics 20, 1165-1173.

MAY, B. \& ROYSE, D. J. (1988). Interspecific allozyme variation within the fungal genus Pleurotus. Transactions of the British Mycological Society 90, 29-36.

Micales, J. A., Bonde, M. R. \& Peterson, J. L. (1986). The use of isozyme analysis in fungal taxonomy and genetics. Mycotaxon 27, 405-449.

Moore, R. T. (1985). Mating type factors in Pleurotus cystidiosus. Transactions of the British Mycological Society 85, 354-358.

OHMASA, M. \& FURUKaWA, H. (1986). Analysis of esterase and malate dehydrogenase isozymes of Lentinus edodes by isoelectric focusing for the identification and discrimination of stocks. Transactions of the Mycological Society of Japan 27, 79-90.

OUdemans, P. \& COFFEY, M. D. (1991). Isoenzyme comparison within and among worldwide sources of three morphologically distinct species of Phytophthora. Mycological Research 95, 19-30.

RADOLA, B. J. (1980). Ultrathin-layer isoelectric focusing in 50-100 $\mu \mathrm{m}$ polyacrylamide gels on silanised plates or polyester films. Electrophoresis 1, 43-56.

RAPER, C. A., RAPER, J. R. \& MILLER, J. R. (1972). Genetic analysis of the life cycle of Agaricus bisporus. Mycologia 64, 1088-1117.

Reinhart, M. P. \& Malamud, D. (1982). Protein transfer from isoelectric focusing gels: the native blot. Analytical Biochemistry 123, 229-235.

RighetTI, P. G. (1986). Isoelectric Focusing: Theory, Methodology and Applications. Edited by T. S. Works \& R. H. Burdon. Amsterdam: Elsevier Biomedical.

Roux, P. \& LABARÈRE, J. (1990). Isozyme characterization of dikaryotic strains of the edible Basidiomycete Agaricus bitorquis (Quél.) Sacc. (syn. Agaricus edulis). Experimental Mycology 14, 101-112.

Roux, P. \& LABARÈRe, J. (1991). Determination of genes and subunit composition of three isozyme activities in Agaricus bitorquis. Mycological Research 95, 851-860.

RoYSE, D. J. \& MAY, B. (1982). Genetic relatedness and its application in selective breeding of Agaricus brunnescens. Mycologia 74, 569575.

ROYSE, D. J., SPEAR, M. C. \& MAY, B. (1983). Cell line authentication and genetic relatedness of lines of the shiitake mushroom, Lentinus edodes. Journal of General and Applied Microbiology 29, 205-216.

Royse, D. J., Jodon, M. H., ANTOUN, G. G. \& MAY, B. P. (1987). Confirmation of intraspecific crossing and single and joint segregation of biochemical loci of Volvariella volvacea. Experimental Mycology 11, 11-18.

Shannon, M. C., Ballal, S. K. \& Harris, J. W. (1973). Starch gel electrophoresis of enzymes from nine species of Polyporus. American Journal of Botany 60, 96-100.

Shaw, C. R. \& Prasad, R. (1970). Starch gel electrophoresis of enzymes: a compilation of recipes. Biochemical Genetics 4, 297320

SiNGER, R. (1986). The Agaricales in Modern Taxonomy. 4th edn. Germany: Koeltz Scientific Books. 
SMITH, M. L. \& ANDERSON, J. B. (1989). Restriction fragment length polymorphisms in mitochondrial DNAs of Armillaria: identification of North American biological species. Mycological Research 93, 247-256.

SNeath, P. H. \& Sokal, R. R. (1973). Numerical Taxonomy. San Francisco: W. H. Freeman.

Willetts, H. J., Byrde, R. J. W., Fielding, A. H. \& Wong, A.-L.
(1977). The taxonomy of the brown rot fungi (Monilinia spp.) related to their extracellular cell wall-degrading enzymes. Journal of General Microbiology 103, 77-83.

Zervakis, G. \& Balis, C. (1991). Pleurotus species of Greece: an evaluation of their morphological and physiological characteristics. Mushroom Science 13, 537-544. 